\title{
Potential Traffic Levels after Increasing the Maximum Vehicle Weight in Environmentally Efficient Transportation System: The Case of Finland
}

\author{
Teijo Palander" ${ }^{*}$, Kalle Kärh $\ddot{a}^{2}$ \\ ${ }^{1}$ Faculty of Science and Forestry, University of Eastern Finland, P.O. Box 111, \\ FI-80101 Joensuu, Finland \\ e-mail: teijo.s.palander@uef.fi \\ ${ }^{2}$ Stora Enso Wood Supply Finland, P.O. Box 309, FI-00101 Helsinki, Finland \\ e-mail: kalle.karha@storaenso.com
}

Cite as: Palander, T., Kärhä, K., Potential Traffic Levels after Increasing the Maximum Vehicle Weight in Environmentally Efficient Transportation System: The Case of Finland, J. sustain. dev. energy water environ. syst., 5(3), pp 417-429, 2017, DOI: http://dx.doi.org/10.13044/j.sdewes.d5.0154

\begin{abstract}
The objective of this research was to study how the maximum vehicle weight (76 t) will affect roundwood transportation in environmentally efficient transportation system. Actual traffic levels were assessed with calculations based on the vehicle configurations $(60,64,68$, and $76 \mathrm{t})$ a year after the weight limit was raised. Consequences of this change were also assessed for predicted future traffic levels. The reduction in operational vehicle-km was $12.5 \%$ (versus a decrease of $9.3 \%$ based on the legal weight), though this may underestimate the long-term prediction $(26.7 \%)$ that will be achieved when the roundwood transportation sector adjusts fully to the higher maximum weight limit. The migration of loads to heavier vehicles did not create any wood harvesting problems for 60, 64 and $68 \mathrm{t}$ vehicle configurations. However, $76 \mathrm{t}$ vehicles were often volume-constrained, so it was harder to achieve the maximum weight. The main operational challenge was pulpwood $(3.5$ and $4.0 \mathrm{~m})$ when onboard loaders were not available. Based on comparison of roundwood length measurements as an indicator of volume-constraint vehicles, the best practice system is discussed to enable an efficient transportation system for sustainable wood procurement.
\end{abstract}

\section{KEYWORDS}

Timber load, Maximum vehicle weight, Environmental efficiency, Sustainable wood procurement.

\section{INTRODUCTION}

The design of logistics systems for sustainable wood procurement for pulp production, including transportation management systems, is based on optimum solutions in the long term [1]. In this respect, along with economic sustainability, based on the idea of continuous forest yield, environmental sustainability has become a serious issue in Finland's forest management debate [2]. Since the 2000's, commitments to wood harvesting as a sustainable forest resource have also strengthened in the Finnish forest industry [3]. The main benefits of environmentally acceptable wood harvesting include

\footnotetext{
${ }^{*}$ Corresponding author
} 
increased supply of sustainable energy resources and reduced Carbon dioxide $\left(\mathrm{CO}_{2}\right)$ gas emissions. According to the authors, economic and environmental sustainability is actually considered at the local level by wood procurement entrepreneurs and companies.

Stora Enso is one of the largest forest industry companies in Europe and it is an important pulp producer in the global forest industry. As a part of the wood procurement of the company, road transportation is used from forests to pulp mills. For example, in Finland, $75 \%$ of the timber used by the forest industry is transported to the mill by 1,700 vehicles [4]. The remaining $25 \%$ is transported to the mill either by train (22\%) or by water $(3 \%)$, although these methods include transporting roundwood for an average of $50 \mathrm{~km}$ at the beginning of the transportation chain. In 2013, the typical vehicle configuration used to support Nordic cut-to-length systems was a three-axle truck pulling a four-axle trailer [5]. To clarify the terminology, a truck is defined henceforth as a tractor with an integrated (non-detachable) load bed. The maximum weight of such vehicles, including payload, was limited to $60 \mathrm{t}$ in 1993 [6]. The maximum weight is often considered to be less important than the axle weight, since the weight per axle determines the damage done to the road. In 2013, the Ministry of Transport and Communications of Finland increased the maximum weight to $76 \mathrm{t}$ for Larger and Heavier Vehicles (LHV) equipped with nine axles (four axles in the truck and five axles in the trailer) (Figure 1). The LHVs retain a similar or lower axle weight, so they should cause less damage to roads, all other factors being held constant. Regardless of the legal weight limit, the vehicles are designed to operate on highways as well as to work under the demanding conditions on narrow forest roads.

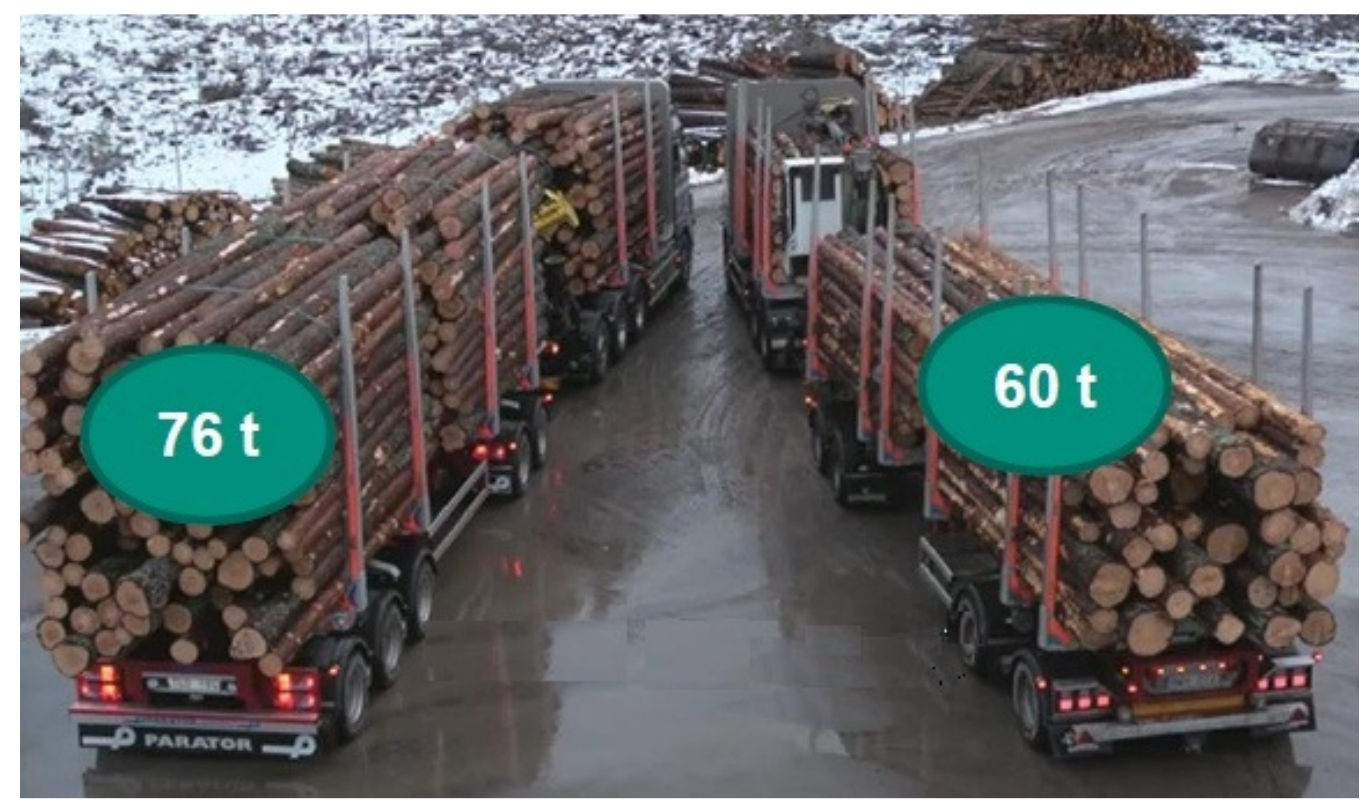

Figure 1. Maximum payloads in 60 and $76 \mathrm{t}$ vehicle configurations (photo: Metsähallitus)

The Finnish forest industry has been demanding the right to transport larger and heavier loads to improve the cost-effectiveness of timber transportation [7]. Their argument is that increasing the legal maximum weight of vehicles will enable entrepreneurs to optimize loads and thus reduce the amount of vehicle travel required to deliver a given quantity of roundwood (Figure 2). Under certain operational conditions, this load factor, i.e. the proportion of the time during which vehicles travel with their full payload, can yield both economic and environmental benefits [8]. However, the vehicle configurations with total weights above $60 \mathrm{t}$ have both strong supporters and strong opponents. Although the transportation efficiency gains are likely to be environmentally large and significant, critics of the proposal point out decreased safety and greater wear 
and tear on roads (particularly during the spring thaw) as potential concerns [9-11]. Furthermore, LHVs have only been used only on specific transportation routes. Therefore, more environmental knowledge about LHVs is needed.

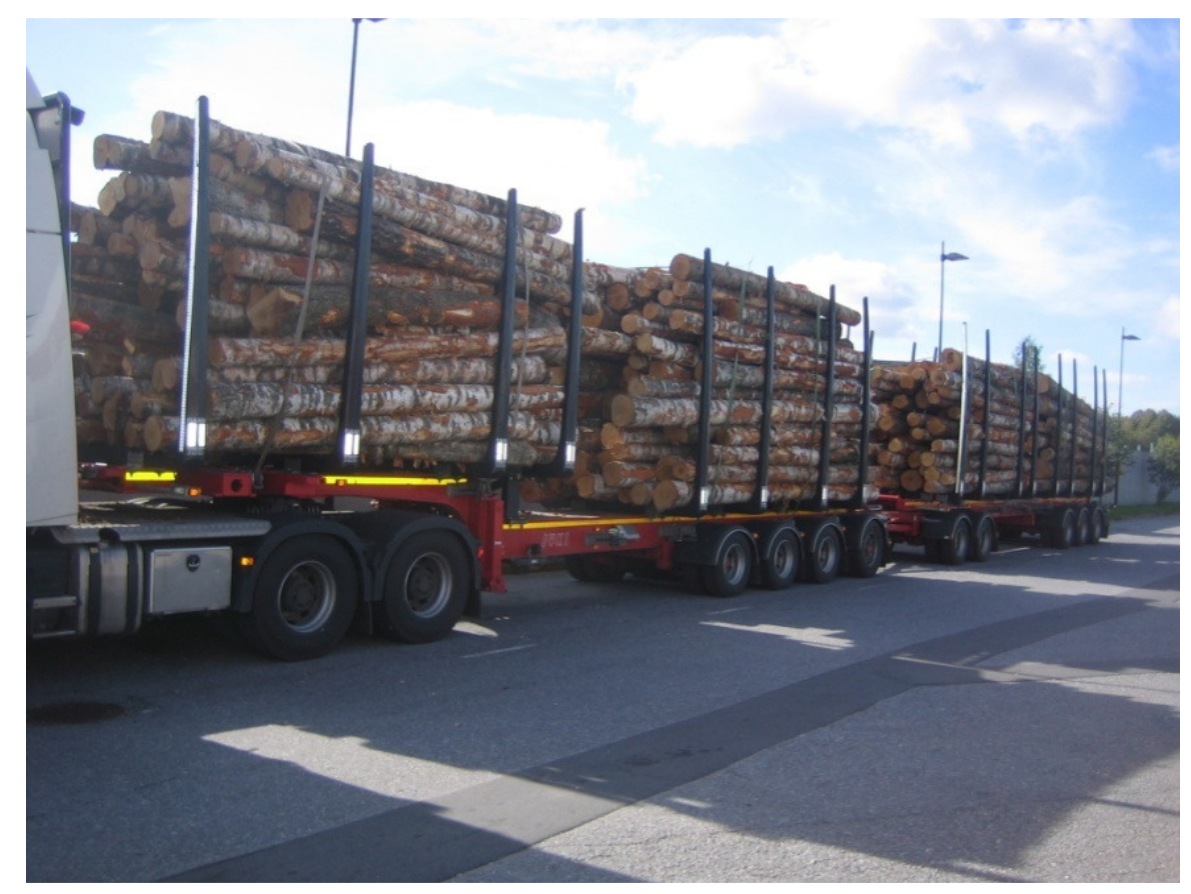

Figure 2. Maximum payload in $90 \mathrm{t}$ vehicle combination (photo: T. Palander)

In Europe, most operational studies have only considered a weight increase from $40 \mathrm{t}$ to $60 \mathrm{t}$ and have not addressed the issues that arise with heavier loads [12]. In the United States and Canada, B-trains equipped with eight axles can exceed $62 \mathrm{t}$ in weight, and the environment is sufficiently similar to that of Finland that the implications of their experience can be discussed for Finland. In the United States, Michigan limits the weight allowed on individual axles, depending upon the spacing between them, and allows a maximum of 11 axles [13]. After B-trains had been implemented in Michigan, the maximum gross vehicle weight still allowed on a vehicle that complies with US federal regulations rather than Michigan regulations was $36 \mathrm{t}$, with four of the vehicle's five axles carrying $7.7 \mathrm{t}$ each. The calculated maximum allowable gross vehicle weight on the heaviest vehicle that complies with Michigan's regulations is $74 \mathrm{t}$, which can be achieved by using 11 properly spaced axles that each carries $6.7 \mathrm{t}$. It would take more than two $36 \mathrm{t}$ trucks to carry the same cargo as a single $74 \mathrm{t}$ Michigan truck. Environmental efficiency research has shown that these two smaller trucks would actually cause about $60 \%$ more pavement damage than the single heavier truck because of their higher axle loadings and the weight of a second tractor (compared with a single tractor for the B-train), at about $10 \mathrm{t}$ per tractor [14].

In Sweden, the increased maximum weights have been justified based on lower transportation costs, lower fuel consumption, and therefore lower emissions of environmental contaminants such as $\mathrm{CO}_{2}$ and diesel particulate matter $[15,16]$. Swedish studies have also suggested that if $60 \mathrm{t}$ vehicle configurations were replaced with $90 \mathrm{t}$ LHVs equipped with eleven axles, this could reduce the total distance driven by as much as $21 \%$ [17]. In addition to improving environmental efficiency, this would decrease annual socio-economic costs by 4\%, if the LHVs use the existing routes and bridges [17]. The low return was due to costs for improving bridge capacity or exceptionally high purchase costs for LHVs or some other factor. In this study, it is explained why the environmental efficiency is low based on the $76 \mathrm{t}$ implications for Finnish LHVs. 
Finnish studies have reported that if the $60 \mathrm{t}$ vehicle configurations were replaced with $76 \mathrm{t}$ LHVs and these LHVs used the same routes and road infrastructure, the larger capacity (Table 1) could decrease $\mathrm{CO}_{2}$ and Nitrogen oxides $\left(\mathrm{NO}_{\mathrm{x}}\right)$ emissions by as much as 32 and $41 \%$, respectively [18]. Increasing the weight limit to $76 \mathrm{t}$ would therefore improve the environmental efficiency of wood transportation. In addition to the environmental benefits and lower transport costs (EUR $200 \times 10^{6}$ per year) [18], this change has been justified based on the smaller stress on the road (a 64\% decrease) caused by the increased number of axles and based on increased road safety caused by a better weight distribution between the truck and trailer (Table 1) [18].

Table 1. Changes in maximum weights and number of axles for the vehicle configurations in Finland

\begin{tabular}{ccccccc}
\hline \multicolumn{2}{l}{ Weight limit [t] } & \multirow{2}{*}{ Old } & New & \multirow{2}{*}{ New no. of axles } & \multicolumn{4}{c}{ Payload } & \multirow{2}{*}{ Duration of change } \\
\cline { 4 - 6 } & 64 & 7 & Old [t] & New [t] & Increase [\%] & \\
\hline 60 & 64 & 8 & 37 & 45 & 22 & Temporary $^{*}$ \\
60 & 68 & 9 & 35 & 51 & 46 & Permanent \\
60 & 76 & Permanent \\
\hline
\end{tabular}

In the present study, it was investigated how transportation entrepreneurs have operated on a local wood procurement environment affected by increased LHV weight and migration to the heavier vehicles. Since the operational impact of the maximum weight limits will depend on the transportation entrepreneurs' desire to use the new trucks and trailers, the analysis assumed a synchronized system in which older and new LHV configurations are used simultaneously, at least during the early stages of adoption of the LHV technology (Figure 3). The objective was to understand how the new maximum vehicle weight $(76 \mathrm{t})$ has affected environmental efficiency of roundwood transportation. The traffic levels are analyzed and described for different vehicle capacities $(64,68$, and 76 t) to reveal what they would offer in an environmentally efficient transport system. Payloads' roundwood lengths are also compared as an indicator of volume-constraint vehicles. In this respect, the aim is to find an optimal solution to payload's roundwood length on $76 \mathrm{t}$ vehicles.

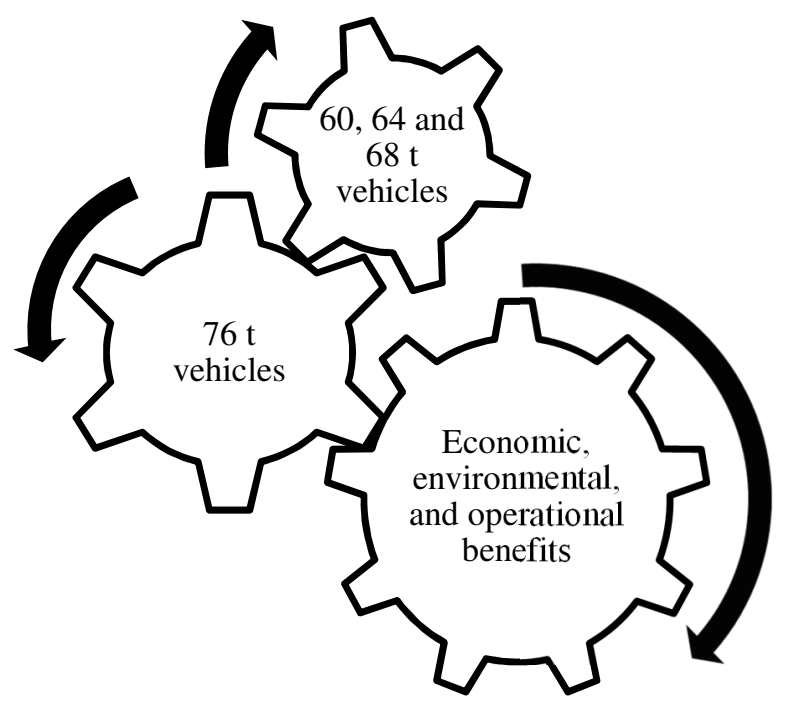

Figure 3. The migration of roundwood transportation to heavier vehicles while smaller vehicles continue to operate will generate benefits due to an increased maximum payload, thereby decreasing transportation costs and pollutant emission 


\section{MATERIALS AND METHODS}

As a main data source, quantitative Enterprise Resource Planning (ERP) data from Stora Enso and Metsähallitus were used to calculate the operational impacts of the new vehicle configurations (Table 2). The weight data is based on 11,530 loads transported from forests to pulp mills of Finnish forest industry. The number of trips per vehicle configuration ranged between 302 and 3,029. Modern vehicles (Models 2012 and 2013) were selected for this study.

Table 2. The average weights of the empty vehicle configurations, vehicles either had or lacked a removable loader

\begin{tabular}{ccccccc}
\hline \multirow{2}{*}{$\begin{array}{c}\text { Maximum } \\
\text { weight limit [t] }\end{array}$} & \multicolumn{3}{c}{ Truck without a loader } & \multicolumn{3}{c}{ Truck with a loader } \\
\cline { 2 - 7 } & $\begin{array}{c}\text { Vehicle } \\
{[\mathrm{kg}]}\end{array}$ & $\begin{array}{c}\text { Truck } \\
{[\mathrm{kg}]}\end{array}$ & $\begin{array}{c}\text { Trailer } \\
{[\mathrm{kg}]}\end{array}$ & $\begin{array}{c}\text { Vehicle } \\
{[\mathrm{kg}]}\end{array}$ & $\begin{array}{c}\text { Truck } \\
{[\mathrm{kg}]}\end{array}$ & $\begin{array}{c}\text { Trailer } \\
{[\mathrm{kg}]}\end{array}$ \\
\hline 60 & 19,976 & 12,207 & 7,771 & 23,609 & 15,935 & 7,675 \\
64 & 19,793 & 12,100 & 7,693 & 23,546 & 15,910 & 7,635 \\
68 & 20,294 & 12,130 & 8,165 & 24,311 & 16,168 & 8,143 \\
76 & 23,370 & 14,834 & 8,536 & 25,894 & 17,470 & 8,425 \\
\hline
\end{tabular}

Figure 4 shows the total transportation quantities $(\mathrm{t} \mathrm{km})$ of the different vehicle configurations. In addition to the total quantities, revised traffic levels were calculated based on each legal maximum weight for the first time. Such an analysis has been performed for Finland in accordance with a procedure that considers the load factor and load migration to heavier vehicles $[8,19]$. A series of Excel spreadsheets was constructed to perform the analysis. It incorporated data on the proportions of loads subject to a weight- and/or volume-constraint. It also allowed for variations in the extent to which weight-constrained loads would migrate from 60,64 , and $68 \mathrm{t}$ vehicles to the $76 \mathrm{t}$ vehicle configurations.

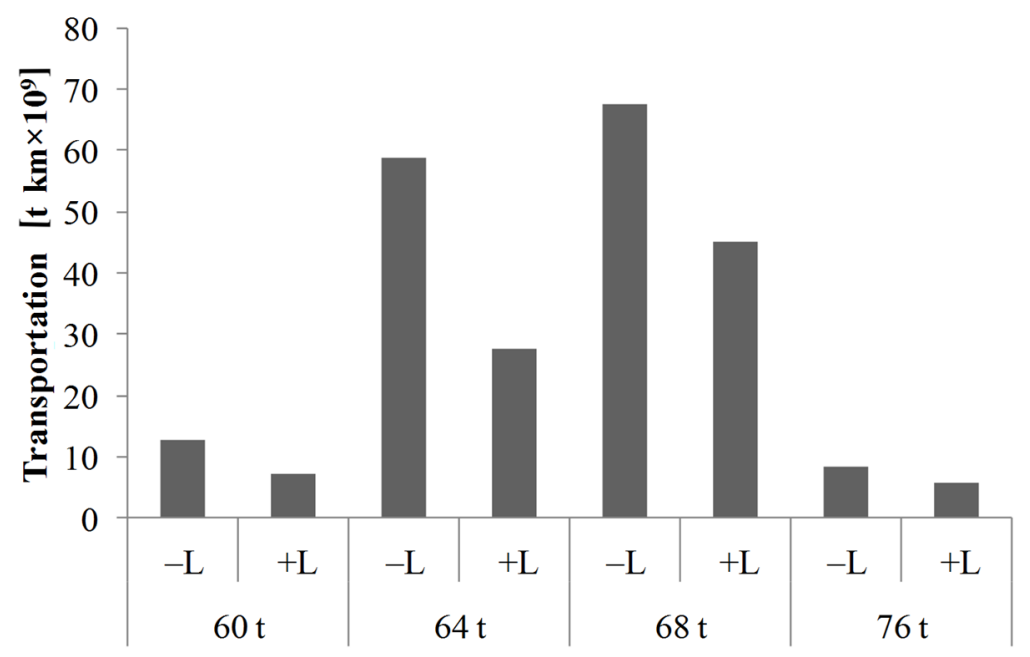

Figure 4. Total roundwood $(\mathrm{t} \mathrm{km})$ transported by Finnish vehicle configurations with different maximum weight limits during the 2014 study period, vehicles either had $(+\mathrm{L})$ or lacked $(-\mathrm{L})$ a removable loader

Actually, timber trucking entrepreneurs are contractors of Stora Enso and Metsähallitus, which are responsible for transportation work. Survey data was used to profile the transportation entrepreneurs and define the most important groups for the calculations and statistical comparisons. The survey provided precise data from LHVs 
and their operational environment. A four page questionnaire was sent to 56 entrepreneurs, all of whom returned the questionnaire (i.e., a 100\% response rate). The questionnaire was divided into seven parts, with questions about the background information, the vehicle configuration, the onboard loader, the truck's load space, the trailer, the trailer's load space, and the operational environment. The $7^{\text {th }}$ part asked about the roundwood transportation operations using open-ended questions.

In our statistical analysis of the operational environment, the vehicle configurations were divided into three groups based on the weights or payloads of the truck, the trailer, and the whole vehicle. These groups were subdivided based on the presence or absence of a loader mounted on the truck; none of the vehicles used a trailer-mounted loader. The average payload per trip can vary greatly as a result of variations in the lengths of the roundwood assortments. For example, the average payload of trucks without a loader was $17.8 \mathrm{t}$ per trip, but ranged from $16.1 \mathrm{t}$ to $21.7 \mathrm{t}$. The data were analyzed using the SPSS-X software [20] in two stages. First, the survey responses were analyzed using Kendall's rank-correlation coefficient $(\tau)$ to detect whether the groups being tested differed significantly in their response to each question. In the second stage, the groups of $76 \mathrm{t}$ vehicle configuration were compared using non-parametric analysis of variance (the Kruskal-Wallis test) and compared these groups two at a time using the Mann-Whitney $U$-test. These statistical tests were used, because the variable values did not show a normal distribution.

\section{RESULTS}

The traffic levels were assessed for four vehicle configurations $(60,64,68$, and $76 \mathrm{t})$ in a synchronized system with all four configurations operating simultaneously. An increase in the maximum weight of the vehicle configurations would decrease the amount of vehicle travel required to deliver the same volume of roundwood to the mills (i.e., improved environmental efficiency). The total reduction in vehicle-km was $12.5 \%$ (versus $9.3 \%$ estimated based on the legal weights). Figure 5 shows the average vehicle and payload weights for the vehicle configurations. For example, the results show that $100 \%$ of the $60 \mathrm{t}$ vehicle configurations were weight-constrained (i.e., the actual weight was greater than the legally mandated weight). For the $60 \mathrm{t}$ vehicles, $45 \%$ of the vehicles weighed $110 \%$ or more of the legal maximum vehicle weight and the remainder $(55 \%)$ weighed $125 \%$ or more of the legal maximum vehicle weight.

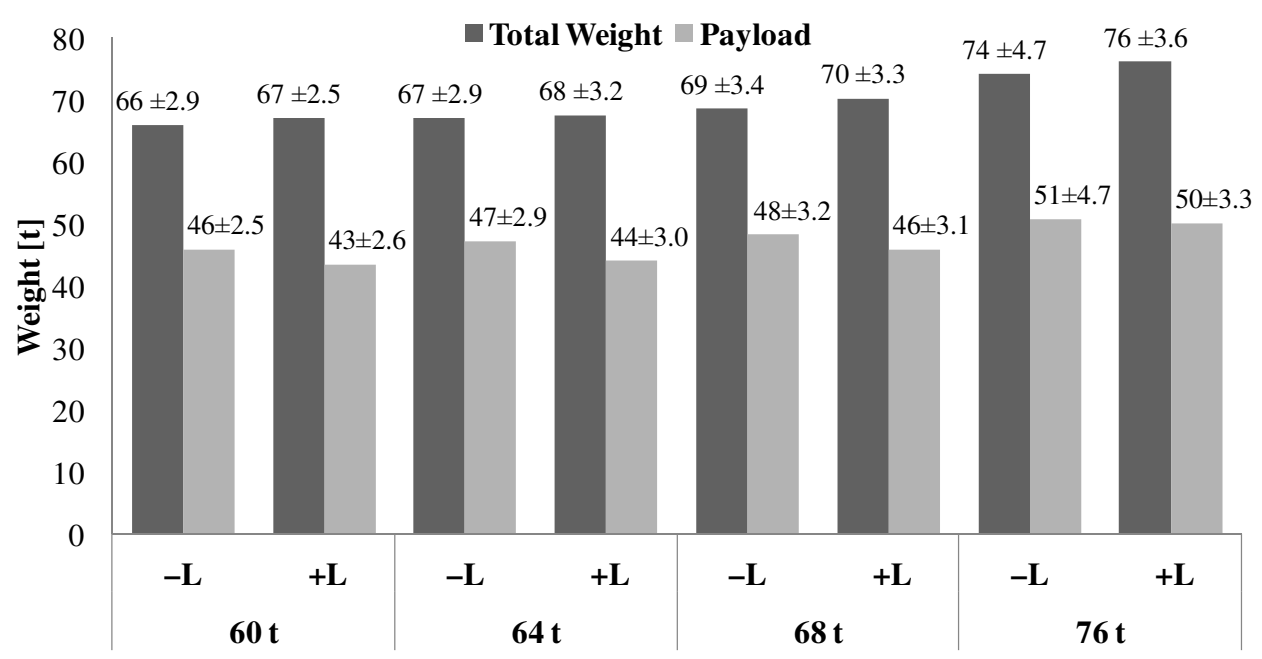

Figure 5. The average total vehicle weights and payloads for configurations with total weights of $60,64,68$, and $76 \mathrm{t}$, vehicles either had $(+\mathrm{L})$ or lacked $(-\mathrm{L})$ a removable loader, standard deviation (mean \pm SD values) for all configurations provides the variation around the mean weight 
Figure 5 also shows that the payload differed among the vehicle configurations, ranging from 43 to $51 \mathrm{t}$. Vehicles' loaders weighed 3 to 4 t. In Finland, the 60, 64, and $68 \mathrm{t}$ vehicle configurations rarely carry less than a full load based on weight. Actually, the 64 and $68 \mathrm{t}$ configurations were also fully loaded. Thus, the payloads carried by these vehicles were close to $100 \%$ of the legal limit. Only the $76 \mathrm{t}$ configurations without a removable loader were not limited by the maximum weight (i.e., worse environmental efficiency). This means that $49 \%$ of these vehicles achieved a gross weight of between 96 and $99 \%$ of the maximum permitted vehicle weight. For $76 \mathrm{t}$ configurations $39 \%$ of the travel distance was also subject to a volume constraint (i.e., the load weight was $<51 \mathrm{t}$ ), and $61 \%$ limited solely by the maximum vehicle weight.

For all vehicles, average transport distance ranged from 106 to $182 \mathrm{~km}$ (Figure 6). The distance was measured by GIS from forest roadside to mill as the travel distance on road. Data of 64 and 68 t vehicles in Figure 6 have non-linear values (abnormally low), because these vehicles were used for short distance transport. Actually, transportation entrepreneurs together with managers of forest industry have decided transport schedules during the planning process of timber transportation. These modules were therefore not so efficient vehicle configurations in the synchronized transport system. In the current system, in which configurations with lower maximum weights continued to transport wood while LHVs were being adopted, the amount of wood being transported by $76 \mathrm{t}$ LHVs will gradually increase, but in the short term, total travel per vehicle will be lower than it will be in the future with the heavier configurations. The system allowed for the possibility that maximum weight increase might generate additional road freight movement per larger vehicle configurations during the adjustment process towards 76 tonnes (i.e., improved environmental efficiency). The average roundwood transport increased from $21 \times 10^{6} \mathrm{t} \mathrm{km}$ for the $60 \mathrm{t}$ vehicles to $27 \times 10^{6} \mathrm{t} \mathrm{km}$ for the $76 \mathrm{t}$ vehicles for configurations without a removable loader (Figure 7). In vehicle configurations equipped with removable loader, the increase was smaller: $17 \times 10^{6} \mathrm{t} \mathrm{km}$ for the $60 \mathrm{t}$ configuration, vs. $21 \times 10^{6} \mathrm{t} \mathrm{km}$ for the $76 \mathrm{t}$ configuration.

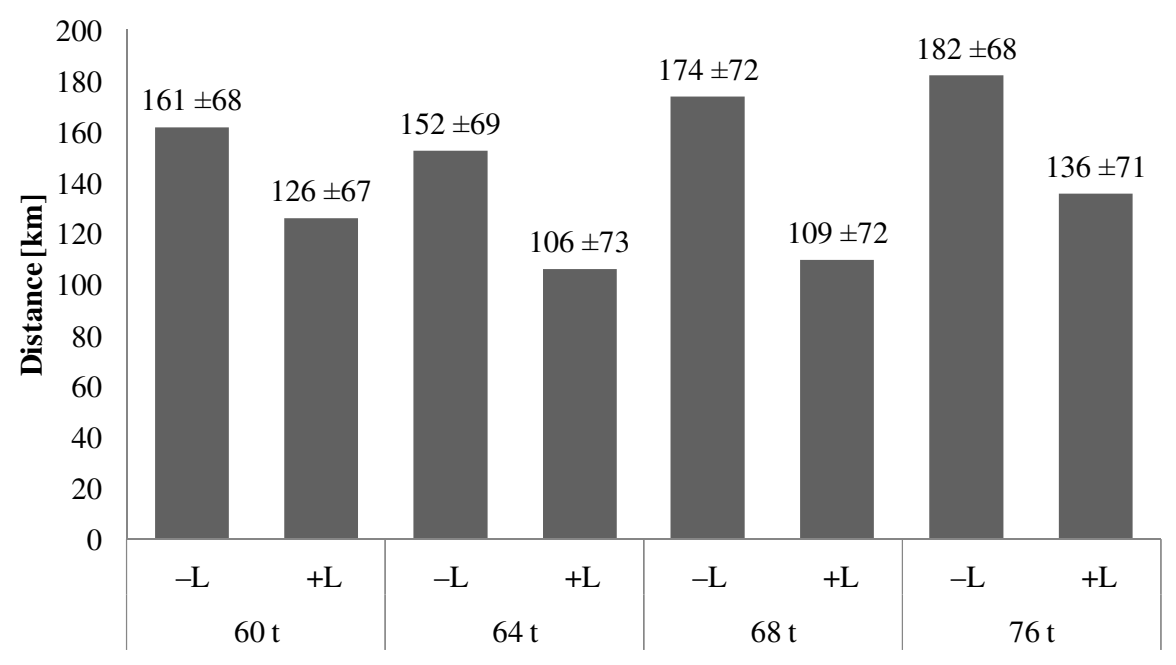

Figure 6 . The average transportation distance travelled by the vehicle configurations with different maximum weight limits, vehicles either had $(+\mathrm{L})$ or lacked $(-\mathrm{L})$ a removable loader, standard deviation (Mean \pm SD values) for all configurations provides the variation around the average transportation distance

The statistical tests were used to study influential factors of environmental efficiency in different operational environments of LHVs. The roundwood length affected the operational environment for the $76 \mathrm{t}$ configurations. Both the total vehicle weight and the payload differed significantly (Kruskal-Wallis, $p \leq 0.05$ ) among roundwood lengths. 
Table 3 shows the effects of roundwood length on the payload for the $76 \mathrm{t}$ configuration. For pulpwood lengths of 3.5 to $4.0 \mathrm{~m}$, operational challenges were observed (i.e., worse environmental efficiency): payloads were significantly less than the maximum payload (55.1 and 52.8 t without and with a detachable loader, respectively). Further, entrepreneurs believed that in addition to length, drying of the roundwood may decrease the wood weight and therefore decrease the payload during the spring and summer. Table 3 shows that payload volume became a more significant constraint than payload weight.

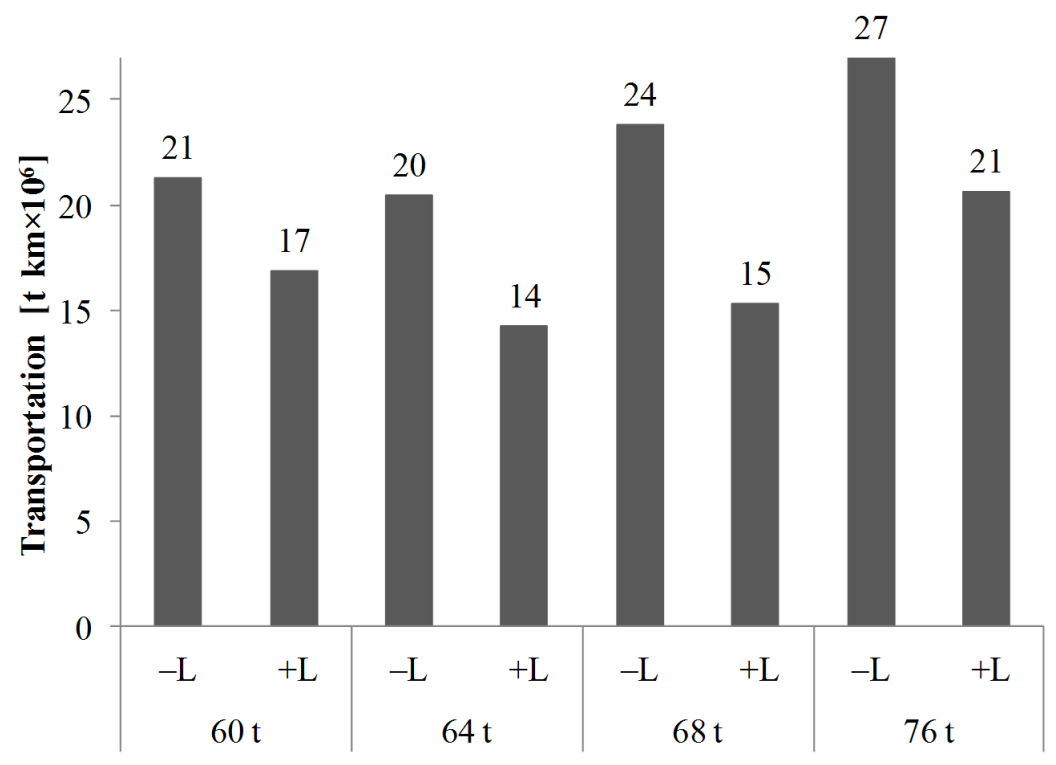

Figure 7. The average roundwood transportation $(\mathrm{t} \mathrm{km})$ by vehicle configurations with different maximum weight limits, vehicles either had $(+\mathrm{L})$ or lacked $(-\mathrm{L})$ a removable loader

Table 3. Effects of roundwood length on the payload transported by the $76 \mathrm{t}$ vehicle configuration, values in a column indicated with asterisks are significantly smaller than the heaviest payload (boldfaced), vehicles either had $(+\mathrm{L})$ or lacked $(-\mathrm{L})$ a removable loader

\begin{tabular}{|c|c|c|c|c|c|c|}
\hline \multirow{3}{*}{$\begin{array}{c}\text { Length of } \\
\text { roundwood } \\
{[\mathrm{m}]}\end{array}$} & \multicolumn{6}{|c|}{ Payload [t] } \\
\hline & \multicolumn{2}{|c|}{ Truck } & \multicolumn{2}{|c|}{ Trailer } & \multicolumn{2}{|c|}{ Whole vehicle } \\
\hline & $-\mathrm{L}$ & $+\mathrm{L}$ & $-\mathrm{L}$ & $+\mathrm{L}$ & $-\mathrm{L}$ & $+\mathrm{L}$ \\
\hline 3.0 & 21.7 & 17.7 & $33.4^{* * * *}$ & $33.0^{* * * * *}$ & 55.1 & $50.5^{* * * *}$ \\
\hline 3.5 & $16.3^{* * *}$ & $15.0^{* * * *}$ & 36.1 & $32.9^{* * * *}$ & $52.1^{* * * *}$ & $48.1^{* * * *}$ \\
\hline 4.0 & $16.1^{* * *}$ & $15.4^{* * * *}$ & $34.0^{* *}$ & $33.5^{* * * *}$ & $50.2^{\text {**** }}$ & $49.0^{* * *}$ \\
\hline 4.5 & $16.8^{* *}$ & 16.8 & 35.0 & 35.8 & $52.0^{*}$ & 52.8 \\
\hline 5.0 & 18.1 & 17.0 & 36.9 & 34.3 & 55.0 & 51.5 \\
\hline
\end{tabular}

According to the survey, the most influential infrastructural factor that entrepreneurs believed would affect their operations was bridge load capacity. The load capacity limited the roundwood transportation because the $76 \mathrm{t}$ vehicle configurations were too heavy for bridge load capacities. The increase in limited bridge capacity and the maximum vehicle weight (from $60 \mathrm{t}$ to $76 \mathrm{t}$ ) increased transport distance travelled and this concern may be important in practice (i.e., worse environmental efficiency). Entrepreneurs also believed that the condition of forest roads were significant concerns that may worse environmental efficiency. The quality of road care was mentioned by $55 \%$ entrepreneurs. 


\section{DISCUSSION}

The Finnish national forecasts have depended heavily on expert judgments of the degree to which the heavier vehicles would be adopted in wood procurement of pulp production. Therefore, the decision to increase the maximum vehicle weight to $76 \mathrm{t}$ starting in 2014 was contentious. Further, calculating the impact of the vehicle weight increase from 60 t to $76 \mathrm{t}$ has been easier in Finland than elsewhere because Finland decouples vehicle weight limits from volume limits by standardizing the weight limit to $76 \mathrm{t}$ across the country and assuming that the road infrastructure can safely accommodate the LHVs [18]. Actually, the wood transportation forecast by the Finnish government also assumes that $76 \mathrm{t}$ vehicles carried more than $95 \%$ of their legal payload during $80 \%$ of the distance they travelled with a load [18]. These assumptions should be tested before widespread implementation of the LHVs. Although there was general agreement that the heavier loads would improve the economics of wood transportation, many suspected that the environment would suffer as a result of a shift from railway to road transportation and that damage to roads would increase [8, 10, 11, 18]. On the other hand, wood transportation entrepreneurs were not confident that the new logistics system would improve the cost-efficiency of their operations, especially for the $76 \mathrm{t}$ vehicle configuration [9]. The same concerns have been discussed in the United Kingdom and the United States, where more research has been done on this issue than in other countries [8]. Based on the Swedish experience with $90 \mathrm{t}$ vehicles [15], operating costs should decrease, but this will need to be validated for the smaller Finnish vehicles (Figure 1).

The present study used data from the Stora Enso and Metsähallitus road freight transportation to determine what has actually happened during a year of experience with the new maximum weight limits (Table 1). Our analysis was facilitated by the availability of operational ERP data on the nature of the physical constraints on loading the LHVs. When these local factors are accounted for, the predicted traffic levels with increasing maximum weights appear to be reasonably accurate. The observed operational reduction in $\mathrm{t} \mathrm{km}$ was $12.5 \%$ (versus a value of $9.3 \%$ based on the legal limit), though this value in turn is likely to underestimate the predicted long-term value $(26.7 \%)$ that could be achieved when the wood transportation sector has fully adjusted to the new maximum weight limit (Figure 5). The national studies appear to have overestimated the load factor of the $76 \mathrm{t}$ vehicle configuration, i.e. the proportion of the time during which vehicles travel with their full payload also depending on the degree of migration from $60 \mathrm{t}$ vehicles to $76 \mathrm{t}$ vehicles. This is important at predicted traffic level, because the savings in $\mathrm{t} \mathrm{km}$ are predicted to surpass the environmental costs [8, 17, 21-24]. For example, the savings surpass the additional expenses required to construct and maintain roads with high bearing capacity and the additional cost of purchasing and maintaining the heavier vehicles. The latter research also suggests that, raising the weight limit could improve environmental efficiency, if the LHVs retain a similar or lower axle weight in the B-trains; if so, they would cause less damage to roads [13]. In future studies, it is planned to analyze the environmental benefits that the LHVs (configurations of 64, 68, and $76 \mathrm{t}$ ) will offer during later phases of the adaptation process, as well as the new traffic levels, road transport costs, and exhaust emissions.

Cut-to-length harvesting is a crucial infrastructural local factor responsible for sustainable roundwood supply to mills in Finland. The results of the present survey suggest that wood transportation entrepreneurs believed that roundwood characteristics (i.e., log length, water content) represent a major complication for their work. This belief is supported by the data in Table 3; taking full advantage of the weight increase permitted by the $76 \mathrm{t}$ vehicle configuration depends strongly on the lengths in the roundwood assortment. Thus, roundwood lengths must be carefully considered when planning the environmentally efficient transportation system. Traffic levels with the $76 \mathrm{t}$ configuration 
were volume-constrained, since the $76 \mathrm{t}$ vehicles had difficulty achieving their maximum legal weight, particularly for vehicles with a detachable loader (Figure 7). Roundwood drying was mentioned by entrepreneurs in this context, but the consequences of this phenomenon on environmental efficiency could be easily handled by predictive models [25]. The load capacity may be limited in roundwood transportation for 520 bridges, which according to the Finnish Transport Administration do not have the required bearing capacity [26]. The increase in limited bridge capacity (from 144 to 520 bridges) suggests that this concern may be important in practice. Entrepreneurs also believed that the condition and maintenance of local forest roads, especially in the winter, would be an important factor in successful roundwood supply when using current LHVs, because the high snowfall can bury roads and leave them impassable by heavy vehicles. It will also be necessary to study the effects of the spring thaw, which reduces the bearing capacity of roads and highways on the use of LHVs. However, due to the tight economic conditions in Finland, it is unlikely that the road maintenance budget will increase as the traffic increases [5]. Thus, to ensure a year-round roundwood supply to the pulp production, additional research will be needed to develop a new logistics system adapted to the use of LHVs.

Local operations of wood transportation are changing towards increased use of LHVs due to constantly tightening environmental regulations that requires improved environmental efficiency. Pajuoja and Hämäläinen [7] also noted that roundwood logistics is demanding new systems for harvesting and transportation and for the whole sustainable wood-procurement system. This is leading towards the development of more cooperative models in which the forest industry, wood transportation entrepreneurs, and harvesting entrepreneurs work together to clearly define the entrepreneurs' responsibilities and provide the necessary computerized support so they can meet these responsibilities $[6,27,28]$. To enhance the transportation environment, entrepreneurs are willing to work with their clients to plan wood procurement based on the use of LHVs $[5,9]$. Therefore, to facilitate the implementation of LHVs, the objectives for a logistics system should be determined quickly.

Our results confirm that the increased maximum weight can yield significant benefits for the Finnish forest industry by improving the environmental efficiency of roundwood transportation. Based on our results, the number of vehicles could be reduced to 1,542 based on the new legal weights if some of the 1,700 conventional $60 \mathrm{t}$ vehicles currently operating in Finland were replaced with LHVs in the following proportions: $8 \% 60 \mathrm{t}$ vehicles, 40\% $64 \mathrm{t}$ vehicles, 47\% $68 \mathrm{t}$ vehicles, and 5\% $76 \mathrm{t}$ vehicles. If the conventional $60 \mathrm{t}$ vehicles could be entirely replaced, with new proportions of $30 \% 64 \mathrm{t}$ vehicles, $30 \%$ $68 \mathrm{t}$ vehicles, and $30 \% 76 \mathrm{t}$ vehicles, the number of vehicles could be reduced to 1,339. These changes (elimination of 158 to 361 vehicles) may have potentially serious effects on employment that should not be neglected. This is a problem in Canada, where entrepreneurs resist new technologies that are beneficial to their clients but would reduce their income. On the other hand, McKinnon [8] noted that long-term results with LHVs elsewhere in the world support proposals to allow larger and heavier vehicle configurations in both Europe and the Nordic countries. To conclude, load migration to heavier vehicles and the growth of maximum weights is ongoing in Finland based on the good experience of Canada and Sweden, where older vehicle configurations are being replaced with 90 t LHVs (Figure 3) [14-17]. As LHVs travel with full loads during most of their travel in Finland, the experience in other areas should be studied to provide insights into the possibility of a further increase in the maximum weight limit. The methodology employed by McKinnon [8] could be used with the synchronized system to evaluate future scenarios in terms of their environmental benefits, though revision of some key parameters related to the load factor, load migration to larger vehicles, changes 
in traffic, and diversion of roundwood from other modes of transportation to trucks would be required based on experiences with the $76 \mathrm{t}$ weight limit.

\section{CONCLUSIONS}

The objective of this research was to investigate and understand how the new maximum vehicle weight $(76 \mathrm{t})$ will affect roundwood transportation in an environmentally efficient transportation system. The reduction in operational vehicle-km was $12.5 \%$, though this may underestimate the long-term prediction $(26.7 \%)$ that will be achieved when the roundwood transportation sector adjusts fully to the higher maximum weight limit. The results show that Finnish $76 \mathrm{t}$ configuration was partly weight-constrained. The national studies appear to have overestimated the environmental efficiency of the $76 \mathrm{t}$ vehicle configuration. Consequences of this lower change should be assessed for predicted future traffic levels that affect environmental efficiency of roundwood transportation. In this respect, it was investigated how transportation entrepreneurs have operated migration to the heavier vehicles. Since the operational impact of the maximum weight limits will depend on the transportation entrepreneurs' desire to use the new trucks and trailers, as the synchronized presented here system can be applied for solving this kind of problems, in which older and new LHV configurations are used simultaneously. The migration of loads to heavier vehicles did not create any wood harvesting problems for 60, 64, and $68 \mathrm{t}$ vehicle configurations. However, $76 \mathrm{t}$ vehicles were often volume-constrained, so it was harder to achieve the maximum weight. The main operational challenge was pulpwood (3.5 and $4.0 \mathrm{~m})$. Based on our comparison of roundwood length measurements as an indicator of volume-constraint vehicles, the system can be used to find an optimal solution to payload's roundwood length on $76 \mathrm{t}$ vehicles and to enable an efficient transportation system for sustainable wood procurement. The results presented in this study will be applicable in Finland, but the system is likely to be generally applicable in LHV configurations that have been developed for other countries, though possibly with some calibration.

\section{REFERENCES}

1. Palander, T., Tactical Models of Wood-procurement Teams for Geographically Decentralized Group Decision making, D.Sc. (Agr. and For.) Thesis, University of Eastern Finland, Faculty of Science and Forestry, Joensuu, Finland, 1998.

2. Siiskonen, H., From Economic to Environmental Sustainability: The Forest Management Debate in $20^{\text {th }}$ Century Finland and Sweden, Environ. Dev. Sustain., Vol. 15, No. 5, pp 1323-1336, 2013, https://doi.org/10.1007/s10668-013-9442-4

3. Palander, T. and Kärhä, K., Adaptive Procurement Guidelines for Automatic Selection of Renewable Forest Energy Sources within a Sustainable Energy Production System, Energies, Vol. 9, No. 3, 155 p, 2016, https://doi.org/10.3390/en9030155

4. Forest Statistic Yearbook 2014, Finnish Forest Research Institute, Helsinki, Finland, 2015.

5. Malinen, J., Nousiainen, V., Palojärvi, K. and Palander, T., Prospects and Challenges of Timber Trucking in a Changing Operational Environment in Finland, Croatian Journal of Forest Engineering, Vol. 35, No. 1, pp 91-101, 2014.

6. Palander, T., Vainikka, M. and Yletyinen, A., Potential Mechanisms for Co-operation between Transportation Entrepreneurs and Customers: A Case Study of Regional Entrepreneurship in Finland, Croatian Journal of Forest Engineering, Vol. 33, No. 1, pp 89-103, 2012.

7. Pajuoja, H. and Hämäläinen, J., Towards more efficient Wood Procurement Logistics (in Finnish), Tuloskalvosarja 5, Metsäteho, Helsinki, Finland, 2012. 
8. McKinnon, A., The Economic and Environmental Benefits of Increasing Maximum Truck Weight: The British Experience, Transportation Research Part D: Transport and Environment, Vol. 10, No. 1, pp 77-95, 2005, https://doi.org/10.1016/j.trd.2004.09.006

9. Statement of Draft for Heavy Duty Vehicles' Measurements and Mass Strategy (in Finnish), SKAL, Helsinki, Finland, 2012.

10.The European Modular Systems, 2013, http://www.modularsystem.eu, [Accessed: 28-May-2015]

11.No Mega Trucks in Europe, 2013, http://www.nomegatrucks.eu/news/, [Accessed: 28-May-2015]

12.Nykänen, L. and Liimatainen, H., Possible impacts of increasing Maximum Truck Weight - Case Finland, Paper presented at Transport Research Arena, Paris, France, 2014.

13.Chatti, K., Manik, A., Salama, H., Brake, N., Haider, S. W., El Mohtar, C. and Suk Lee, H., Effect of Michigan Multi-axle Trucks on Pavement Distress and Profile, Department of Civil and Environmental Engineering, Michigan State University, RC-1504, Michigan, USA, 2009.

14.Michigan Trains' Productive and Safe, with a flaming Exception Years ago, Truckinginfo, 2013, http://www.truckinginfo.com/news/list.aspx, [Accessed: 28-May-2015]

15.Löfroth, C. and Svenson, G., ETT - Modular System for Timber Transport - One More Stack (ETT) and Bigger Stacks (ST) (in Swedish), Skogforsk, Stockholm, Sweden, Arbetsrapport 758, 2012.

16.Anderson, G. and Frisk, M., Forestry Transportation 2010 (in Swedish), Skogforsk, Stockholm, Sweden, Arbetsrapport 791, 2013.

17.Haraldsson, M., Jonsson, L., Karlsson, R., Vierth, I., Yahya, M-R. and Ögren, M., Cost benefit analysis of Round Wood Transports using 90-tonne Vehicles, VTI, Stockholm, Sweden, VTI rapport 758, 2012, http://www.vti.se/sv/publikationer/samhallsekonomisk-analysav-rundvirkestransporter-med-90-tonslastbilar/, [Accessed: 28-May-2015]

18.Better Competitiveness through new Masses and Dimensions for Heavy Goods Vehicles, Finnish Ministry of Transport and Communications, Helsinki, Finland, 2013.

19.Commission for Integrated Transport, Interim Report: Permitting 44 tonne Lorries for General use in the UK, Commission for Integrated Transport, London, UK, 2000, http://www.cfit.gov.uk/reports/44tonne/pdf/44tonne.pdf, [Accessed: 28-May-2015]

20.SPSS Inc., SPSS-X User's Guide, $3^{\text {rd }}$ ed., SPSS Inc., Chicago, USA, 1988.

21.McKinnon, A. C., Improving the Sustainability of Road Freight Transport by Relaxing Truck Size and Weight Restrictions, Proceedings, Evangelista, P., McKinnon, A. C., Sweeney, E. and Esposito, E., Supply Chain Innovation for Competing in Highly Dynamic Markets: Challenges and Solutions, IGI Global, New York, USA, 2011.

22.McKinnon, A. C. and Piecyk, M., Measurement of $\mathrm{CO}_{2}$ Emissions from Road Freight Transport: A Review of UK Experience, Energy Policy, Vol. 37, No. 10, pp 3733-3742, 2009, https://doi.org/10.1016/j.enpol.2009.07.007

23.Emission Standards, DieselNet, 2014, https://www.dieselnet.com/standards/ eu/nonroad.php, [Accessed: 15-May-2015]

24.Korzhenevych, A., Dehnen, N., Bröcker, J., Holtkamp, M., Meier, H., Gibson, G., Varma, A. and Cox, V., Update of the Handbook on External Costs of Transport, European Commission, DG Mobility and Transport, 2014.

25.Palander, T. S., A Model to estimate Benefits from Log drying for Supply Chains in Wood Procurement, Proceedings, Sjöström, K. and Rask, L. O., $2^{\text {nd }}$ World Symposium on Logistics in Forest Sector, IUFRO and Wood Logistics Network, Växjö, 2001, www.researchgate.net/profile/Teijo_Palander/publications?sorting=newest\&page=2, [Accessed: 28-May-2015] 
26.Pöyskö, T., Sirkiä, A. and Lapp, T., New Maximum Measures and Weights of Heavy Duty Vehicles (in Finnish), 2014, www.ely-keskus.fi/julkaisut । www.doria.fi/ely-keskus, [Accessed: 28-May-2015]

27.Palander, T. and Väätäinen, J., Impacts of Inter-enterprise Collaboration and Backhauling on Wood Procurement in Finland, Scand. J. For. Res., Vol. 20, No. 2, pp 177-183, 2005, https://doi.org/10.1080/02827580510008301

28.Palander, T., Säynäjoki, T. and Högnäs, T., New Organization Models for Timber Car Transport (in Finnish), Metsätieteen Aikakauskirja, No. 1, pp 5-22, 2006.

Paper submitted: 21.09.2016

Paper revised: 07.12.2016

Paper accepted: 08.12.2016 